\title{
Multiple Biological Activities of Human Recombinant Interleukin 1
}

\author{
Charles A. Dinarello,* Joseph G. Cannon," James W. Mier,* Harry A. Bernheim,‡ Gail LoPreste," Debra L. Lynn,\$ \\ Richard N. Love,\$ Andrew C. Webb," Philip E. Auron, ${ }^{\star} \|$ Roberta C. Reuben, ${ }^{\star \star}$ Alexander Rich, \\ Sheldon M. Wolff," and Scott D. Putney\$ \\ *Department of Medicine, Tufts University School of Medicine and the New England Medical Center, Boston, Massachusetts 02111; \\ $\ddagger$ Department of Biology, Tufts University, Medford, Massachusetts 02155; §Repligen Corporation, Cambridge, Massachusetts 02139; \\ "Department Biological Sciences, Wellesley College, Wellesley, Massachusetts 02181; \Department of Biology, Massachusetts Institute of \\ Technology, Cambridge, Massachusetts 02139; **Cistron Technology, Inc., Pine Brook, New Jersey 07053
}

\begin{abstract}
Complementary DNA coding for human monocyte interleukin 1 (IL-1), pI 7 form, was expressed in Escherichia coli. During purification, IL-1 activity on murine $T$ cells was associated with the recombinant protein. Homogeneous human recombinant IL1 (hrIL-1) was tested in several assays to demonstrate the immunological and inflammatory properties attributed to this molecule. hrIL-1 induced proliferative responses in a cloned murine $T$ cell in the presence of suboptimal concentrations of mitogen, whereas no effect was observed with hrIL-1 alone. At concentrations of $0.05 \mathrm{ng} / \mathrm{ml}$, hrIL-1 doubled the response to mitogen $\left(5 \times 10^{6}\right.$ half maximal units/mg). Human peripheral blood $\mathrm{T}$ cells depleted of adherent cells underwent a blastogenic response and released interleukin 2 in the presence of hrIL-1 and mitogen. hrIL-1 was a potent inflammatory agent by its ability to induce human dermal fibroblast prostaglandin $\mathbf{E}_{2}$ production in vitro and to produce monophasic (endogenous pyrogen) fever when injected into rabbits or endotoxin-resistant mice. These studies establish that the dominant pI 7 form of recombinant human IL1 possesses immunological and inflammatory properties and acts on the central nervous system to produce fever.
\end{abstract}

\section{Introduction}

Although the activated monocyte/macrophage produces a great number and variety of biologically active molecules (1), considerable attention has focused on interleukin 1 (IL-1) ${ }^{1}$ as an important mediator of host responses to microbial and inflammatory diseases. There presently is increasing evidence that IL-1 is the primary inducer of many components of systemic "acute-phase" responses and is also responsible for local inflammatory changes in various joint diseases (2-4). There are many biological activities attributed to IL-1 including its effects on the endocrinologic, nervous, and immunological systems. In addi-

Address reprint requests to Dr. Dinarello, Tufts University School of Medicine, 136 Harrison Avenue, Boston, MA 02111.

Received for publication 15 November 1985 and in revised form 10 February 1986

1. Abbreviations used in this paper: CTLL, cytotoxic T lymphocyte line; FCS, fetal calf serum; hrIL-1, human recombinant interleukin 1; IL-1, interleukin 1; LAF, lymphocyte activating factor; NA, nonadherent; $\mathrm{PGE}_{2}$, prostaglandin $\mathrm{E}_{2} ; \mathrm{PHA}$, phytohemagglutinin; SDS-PAGE, sodium dodecyl sulfate-polyacrylamide gel electrophoresis.

J. Clin. Invest.

(c) The American Society for Clinical Investigation, Inc.

0021-9738/86/06/1734/06 \$1.00

Volume 77, June 1986, 1734-1739 tion, in mesenchymal tissue such as cartilage, bone, muscle, and fibrous tissue, IL-1 induces changes associated with both destructive as well as reparative functions. How a single molecule can affect these seemingly opposite activities in a wide variety of cells remains a challenging biological question.

Initial experiments suggesting a broad role for IL-1 in mediating host responses to infection and injury demonstrated that highly purified monocyte-derived endogenous pyrogens were able to augment $T$ cell proliferation to mitogens and antigens, a property known as lymphocyte activating factor $(\mathrm{LAF})(5,6)$; in addition to causing fever, IL-1 induced several components of the acute phase response in experimental animals (7). Recent studies from several laboratories using IL-1 purified from mononuclear phagocytes to apparent homogeneity as judged by sodium dodecyl sulfate-polyacrylamide gel electrophoresis (SDSPAGE) have confirmed the initial observations on the multiple biological activities of IL-1 (8-11). Multiple biological activities of IL-1 are also associated with molecules eluting from gel-filtration chromatography at 30,000-38,000 mol wt (12-14) and with molecules focusing at distinct isoelectric points $(\sim 7,6$, and $5)(6,10,12,13)$; antibodies developed to individual charged forms do not cross react (15). In addition, small fragments of 4,000 and 2,000 mol wt IL-1 derived from human sources have been described and raise the possibility that the active site for some biological activities is segregated in small peptides (16-18).

The sequence of a cDNA coding for human monocyte IL1 has been recently described (19); the derived polypeptide sequence is a precursor form of $31,000 \mathrm{~mol} \mathrm{wt}$ and a $\mathrm{pI}$ near 5, whereas the mature cleavage peptide has a molecular weight of 17,500 and a pI near 7. Although another human monocyte IL1 cDNA has been reported (20), it shares nearly $80 \%$ homology with the amino acid sequence reported for the murine IL-1 from the P388D cell line (21), which has a pI of 5. It is clear from both protein and messenger RNA (mRNA) measurements that the $\mathrm{pI} 7$ form of human IL-1 is the predominant form. As much as $5 \%$ of the total poly A mRNA extracted from human monocytes stimulated with endotoxin codes for this form of IL-1 (22) and this form is also the predominant IL-1 found in human pathological fluids. In this report we describe multiple biological activities of purified human recombinant IL-1 (hrIL-1), which was expressed in $E$. coli, and contained amino acids 71-269. $(24,500 \mathrm{~mol} \mathrm{wt})$ or $112-269(17,500 \mathrm{~mol} \mathrm{wt})$ of the precursor polypeptide $(31,000 \mathrm{~mol} \mathrm{wt})$. The recombinant proteins exhibit several biological properties associated with the immunological and inflammatory properties of the molecule.

\section{Methods}

Materials. Phytohemagglutinin (PHA) was purchased from BurroughsWellcome \& Co. (Research Triangle, NC). All endotoxin determinations 
were made using the Limulus test using lysate with a sensitivity of 20 $\mathrm{pg} / \mathrm{ml}$ obtained from Associates of Cape Cod (Woods Hole, MA). Polymyxin B was purchased from Pfizer Inc., New York, NY and dissolved in pyrogen-free water.

Purification of human monocyte-derived IL-1. Human platelet-pheresis byproducts were used as a source of mononuclear cells; the mononuclear cells were adjusted to a concentration of $1 \times 10^{7} / \mathrm{ml}$ in RPMI1640 (Microbiological Associates, Inc., Bethesda, MD) without methionine containing $1 \%$ dialyzed human $\mathrm{AB}$ serum. Cells were incubated at $37^{\circ} \mathrm{C}$ for $1.5 \mathrm{~h}$ and the nonadherent cells were removed by vigorous shaking. The adherent cell population was stimulated with opsonized heat-killed Staphylococcus albus in the presence of methionine-free medium containing $50 \mu \mathrm{Ci} / \mathrm{ml}$ of $\left[{ }^{35} \mathrm{~S}\right]$ methionine and incubated for $36 \mathrm{~h}$. The supernate was removed, centrifuged at $3,000 \mathrm{~g}$, and filtered. The supernate was purified by sequential immunoabsorption, gel-filtration, and chromatofocusing. Details of the purification procedures and the antibody used to make the immunoabsorbent have been published previously $(10,23)$. IL-1 with pI 6.8-7.2 eluted from the chromatofocusing step as homogeneous $17,500 \mathrm{~mol}$ wt determined by SDS-PAGE fluorography (23); fractions were pooled and used as the IL-1 monocyte standard.

hrIL-1. The IL-1 cDNA expression vector was constructed by isolating the 1112 bp NcoI-XmnI fragment (bp 295-1407) from the IL-1 cDNA plasmid pcD 12-1-8 (19) and inserting it into an E. coli expression plasmid. The hrIL-1 is 223 amino acids long and contains 199 of the 269 amino acid long IL-1 precursor. The amino terminal 24 amino acids are contributed by the expression vector. The hrIL-1 included 46 amino acids of the IL-1 precursor peptide, which are present before the alanine at position 117. This alanine is the N-terminus of the processed IL-1 found in the supernates of stimulated human blood monocytes (24). The predicted molecular weight of the hrIL-1 is 24.5 . hrIL-1-producing bacteria were grown at $37^{\circ} \mathrm{C}$, lysed, and the hrIL-1 was extracted from the insoluble cellular fraction with $8 \mathrm{M}$ urea. hrIL-1 was purified by sequential ion-exchange and either gel-filtration chromatography or high performance liquid chromatography. The hrIL-1 was stored at $-70^{\circ} \mathrm{C}$ in a $0.15 \mathrm{M}$ phosphate-buffered saline, $\mathrm{pH}$ 6.8. The identity of the purified hrIL-1 was confirmed by amino acid composition and the sequence of the amino terminal heptapeptide. Protein concentration was determined by the Bradford method using a bovine serum albumin (BSA) standard. Purity was assessed by SDS-PAGE with Coomassie Blue or silver staining (Fig. 1). The hrlL-1 is estimated to be $>99 \%$ pure. The endotoxin concentration of the hrlL-1 was $\sim 20 \mathrm{pg} / \mu \mathrm{g}$ of IL-1 protein.

In subsequent experiments for pyrogen assays in rabbits, 41 amino acids of the precursor peptide were removed by enzymatic digestion, which yielded hrlL-1 with an N-terminus at the alanine position 112 and a molecular weight of 17,500 . This form of IL-1 is similar to the mature peptide purified from monocytes with the $\mathrm{N}$-terminus at alanine position 117 (24). This recombinant form of IL-1 from amino acid 112 269 was homogeneous on SDS-PAGE and contained 60 pg of endotoxin/ mg of IL-1 protein.

$L A F$ assay. For the costimulator assay, the cloned murine helper $\mathrm{T}$ cell line, D.10.4G.1 was used (25). Previous studies revealed that this $T$ cell line is sensitive to human monocyte IL-1 preparations (26). Dilutions of IL-1 were made in RPMI containing 5\% heat-inactivated fetal calf serum (FCS) and $25 \mu \mathrm{g} / \mathrm{ml}$ of polymyxin B. For the assay, $100 \mu \mathrm{l}$ of each dilution was added to flat-bottom microtiter wells in triplicate. The T cells were used 10-14 d after the last feeding, washed and suspended in $5 \%$ FCS/RPMI at $2 \times 10^{5}$ cells $/ \mathrm{ml}$. All wells received $100 \mu$ l of the T cell suspension containing $1 \mu \mathrm{g} \mathrm{PHA} / \mathrm{ml}$. The proliferative responses of these cells were measured by uptake of tritiated thymidine after $72 \mathrm{~h}$.

Human $T$ cell responses. Human peripheral blood $\mathrm{T}$ cells were purified by a combination of adherence to plastic and nylon wool. T cells ( 5 $\times 10^{6} / \mathrm{ml}$ ) were incubated for $3 \mathrm{~d}$ in flat-bottom wells in the presence of various concentrations of hrlL-1 and/or PHA $(0.5 \mu \mathrm{g} / \mathrm{ml})$. During the last $12 \mathrm{~h}$, cells were pulsed with $\left[{ }^{3} \mathrm{H}\right]$ thymidine and then harvested. For IL-2 production, cells were incubated in round-bottom culture tubes for $3 \mathrm{~d}$ in $10 \mathrm{mM}$ hydroxyurea and the presence or absence of hrlL-1 and $0.5 \mu \mathrm{g} / \mathrm{ml}$ PHA. The supernatants were dialyzed and assayed for IL-2

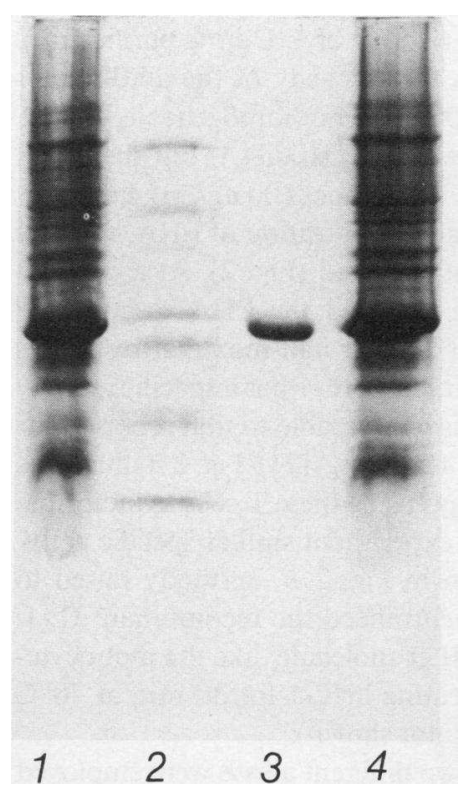

Figure 1. SDS-PAGE of hrIL-1 used in these studies. The gel was loaded with the crude urea extract from the recombinant IL-1 strain (lanes 1 and 4 ). Purified hrIL-1 $(50 \mu \mathrm{g})$ is shown in lane 3. Lane 2 contains marker proteins. using an assay based upon incorporation of $\left[{ }^{3} \mathrm{H}\right]$ thymidine in IL-2-dependent PHA-activated cultured human T lymphocytes (27). Control cultures were stimulated with known concentrations of recombinant IL2 (Cetus Corp., Berkeley, CA). 2-d supernatants were also assayed for IL-2 using an IL-2-dependent cytotoxic T lymphocyte line (CTLL). All error bars shown in figures represent mean cpm \pm SD.

Pyrogen assays. A modification of the mouse pyrogen assay (28) was used. $\mathrm{C} 3 \mathrm{H} / \mathrm{HeJ}$ mice (Jackson Laboratories, Bar Harbor, ME) were implanted subcutaneously with radiotransmitting thermosensors (Minimitter, Sun River, OR). Each thermosensor was calibrated prior to implantation. Temperatures were recorded every $10 \mathrm{~min}$ using a digital analogue of frequency intervals received from an AM radio (29). Mice were placed in a $34^{\circ} \mathrm{C}$ infant isolette for $1.5 \mathrm{~h}$ and baseline temperature was calculated during $60 \mathrm{~min}$ before intraperitoneal injection. Rabbits (New Zealand-derived albino females) weighing $2.5 \mathrm{~kg}$ were used for pyrogen testing as previously described (23). Temperatures were recorded every minute using a Kaye Instruments Digistrip II recorder (Bedford, MA). The data represent the first day responses of trained rabbits to hrIL-1. Three rabbits given $1 \mu \mathrm{g} / \mathrm{kg}$ were used in the group that received $10 \mu \mathrm{g} / \mathrm{kg}$. Rabbits were given daily injections of hrlL-1 in order to induce pyrogenic tolerance; the day 2-5 responses of these rabbits were not used to calculate the mean fevers.

Dermal fibroblast $P G E_{2}$ production. Newborn human foreskin fibroblast cultures were seeded onto 2-ml flat-bottom wells (Costar, Cambridge, MA) and grown to confluence in RPMI containing $5 \%$ FCS as previously described (30). $24 \mathrm{~h}$ before the addition of IL-1, cells were washed and incubated overnight in RPMI without serum. IL-1 dilutions were made in serum-free RPMI and were used to replace the overnight medium. After $24 \mathrm{~h}$, fibroblast supernates were removed and frozen at $-70^{\circ} \mathrm{C}$. Prostaglandin $\mathrm{E}_{2}\left(\mathrm{PGE}_{2}\right)$ concentration was determined by radioimmunoassay (Seragen Inc., Boston, MA).

\section{Results}

Activity of hrIL-1 in the murine LAF assay. The LAF activity of the urea extracts from the recombinant $E$. coli containing the IL-1 insert was compared to urea extracts from recombinant $E$. coli containing the expression plasmid but without the IL-1 sequence. The protein content of the two extracts was adjusted to the same concentration. When diluted, the extracts from the recombinant IL-1-containing strain had considerably more activity than those from the control strain (stimulation indices of $30.6,15.3$, and 3.8 for dilutions of $1: 1,000,1: 10,000$, and 
$1: 100,000$ vs. $8.3,1.7$, and 1.2 , respectively). During purification, LAF activity corresponded to the intensity of the $24,000-\mathrm{mol}$ wt protein staining in SDS-PAGE. The homogeneous hrIL-1 was tested on the murine T cell line, D10.G4.1, but there was no proliferative responses to hrIL-1 alone $(100 \mathrm{ng} / \mathrm{ml})$; however, in the presence of a suboptimal concentration of PHA, marked increases in thymidine uptake occurred (Fig. 2). At a concentration of $0.05 \mathrm{ng} / \mathrm{ml}$, hrIL-1 doubled the PHA response $(P$ $<0.05$, Student's paired $t$ test). Using half-maximal responses as the definition of an IL- 1 unit, the hrIL- 1 has a specific activity of $5 \times 10^{6} \mathrm{U} / \mathrm{mg}$ protein and is comparable to that reported for recombinant murine IL-1 $\left(6 \times 10^{6} \mathrm{U} / \mathrm{mg}\right)(21)$. Fig. $2 A$ illustrates 1 of more than 20 separate assays using these $T$ cells as indicators of hrIL-1 activity and in each experiment similar specific activities were observed. As shown in Fig. $2 \mathrm{~B}$, antibody raised to human monocyte IL-1 (23) neutralized the recombinant IL-1. In addition, the recombinant IL-1 molecule, like the monocytederived IL-1, is heat labile; heating hrIL-1 for $30 \mathrm{~min}$ at $70^{\circ} \mathrm{C}$ reduced activity by $75 \%$ (data not shown).

Human $T$ cell responses. Two different assays were employed using human $\mathrm{T}$ cells stimulated in the presence of hrIL-1 and mitogen. A human $\mathrm{T}$ cell blastogenesis experiment is shown in Fig. $3 A$ that illustrates that hrIL-1 in the absence of PHA has no effect on $T$ cell proliferation. In the presence of PHA, however, hrIL-1 at concentrations of 100 and $10 \mathrm{ng} / \mathrm{ml}$ induced human $\mathrm{T}$ cell proliferative responses. In another assay, human peripheral blood T cell IL-2 production was measured during a 3-d incubation. During the incubation period, hydroxyurea was added to reduce IL- 2 binding to the T cells. Supernatant and control media were dialyzed and assayed on IL-2-sensitive $T$ cells. As

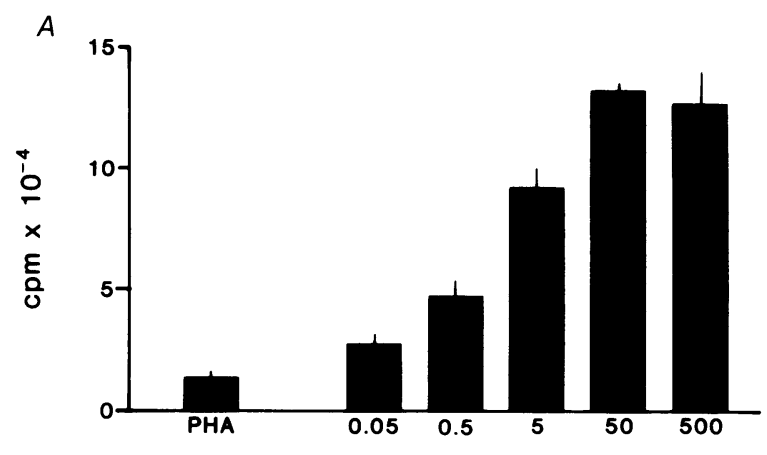

hrlL-1 (ng/ml) +PHA

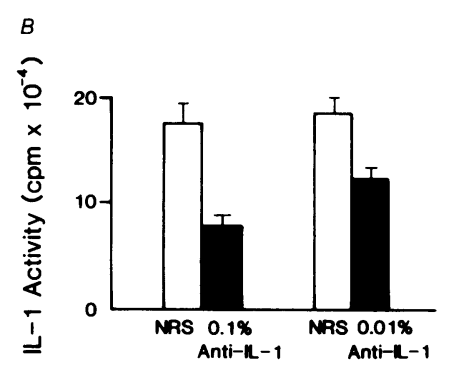

Figure 2. (A) Proliferative responses of D10.G4.1 cells to hrIL-1 in the presence of PHA. Concentration of hrIL-1 is indicated under the horizontal axis. $(B)$ Effect of antimonocyte IL-1 on hrIL-1. hrIL-1 (5 ng/ $\mathrm{ml}$ ) was incubated with either normal rabbit serum (NRS) or anti-IL-1 at the concentrations (vol/vol) indicated for $2 \mathrm{~h}$ at $37^{\circ} \mathrm{C}$ before being added to the D10.G4.1 cells. PHA $=2,533 \pm 322 \mathrm{cpm}$; the response to $5 \mathrm{ng} / \mathrm{ml}$ of hrIL-1 with or without the NRS was within $10 \%$. shown in Fig. $3 B$, hrIL-1 did not induce IL-2 unless PHA was present; significant IL-2 production occurred at IL-1 concentrations of $5 \mathrm{ng} / \mathrm{ml}$.

Additional experiments were carried out in which human $\mathrm{T}$ cells depleted of monocytes by adherence followed by two passages over nylon wool. These nonadherent cells ( $T$ cells) were then incubated with PHA in the presence of various concentrations of hrIL-1 (as above) for $2 \mathrm{~d}$ and the supernatant medium dialyzed before assay. These supernatants were assayed on CTLL cells for the presence of IL-2. In Fig. 4, we show that under these conditions, hrIL-1 in the presence of PHA induced IL-2 from nonadherent (NA) cells at levels comparable to those from unfractionated mononuclear cells incubated with the mitogen. NA cells stimulated with mitogen in the absence of IL-1 produced significantly less IL-2 but this level was severalfold greater than CTLL responses to unconditioned medium $(\mathrm{cpm}=346 \pm 52)$.

Fibroblast $P G E_{2}$ production. hrIL-1 is a potent inducer of $\mathrm{PGE}_{2}$ synthesis in human foreskin fibroblasts. As shown in Fig. 5 , hrIL-1 stimulated dermal fibroblast $\mathrm{PGE}_{2}$ production at concentrations of $5-500 \mathrm{ng} / \mathrm{ml}$. Concentrations of $0.5 \mathrm{ng} / \mathrm{ml}$ induced small but significant levels $(P<0.05)$. The fibroblasts do not produce $\mathrm{PGE}_{2}$ under the same conditions when incubated $24 \mathrm{~h}$ in the presence of as much as $1 \mu \mathrm{g} / \mathrm{ml}$ of endotoxin (30).

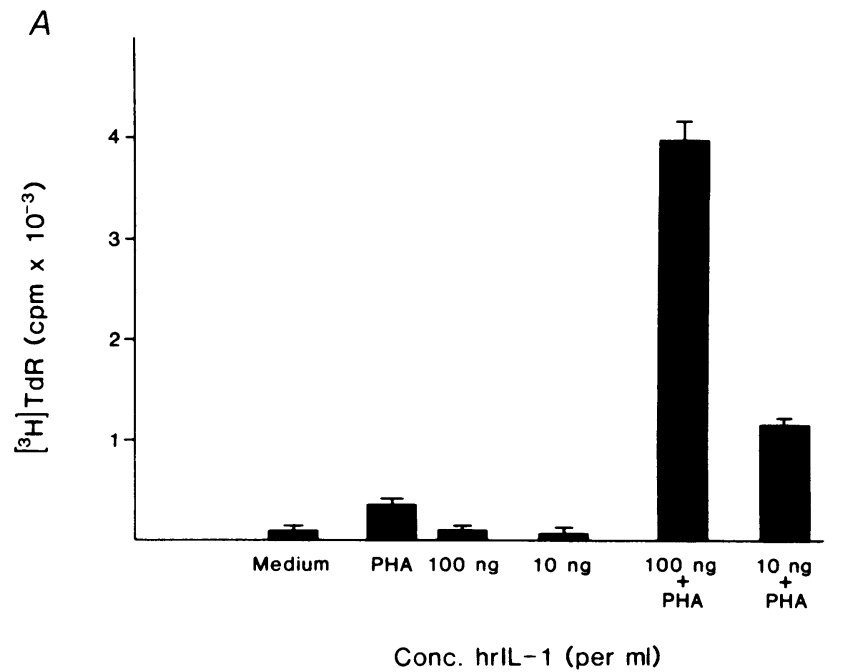

$B$

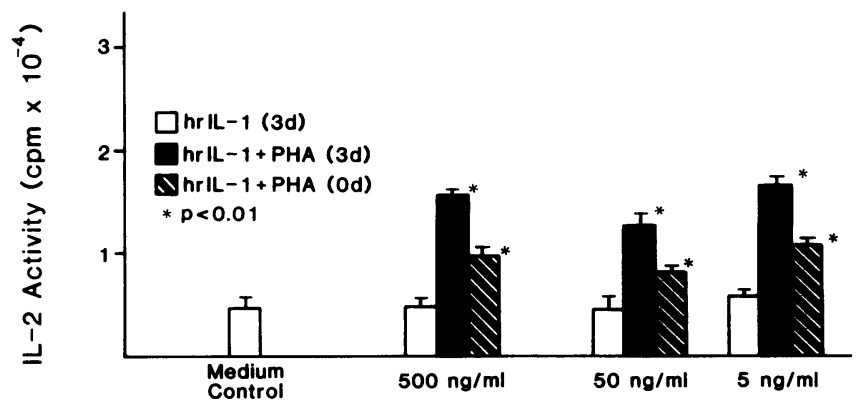

Figure 3. (A) Human T cell blastogenic response to hrIL-1 and PHA. Responses of unfractionated cells to $0.5 \mu \mathrm{g} / \mathrm{ml}$ PHA were $9,533 \pm 76$. Concentration of hrlL-1 is indicated under the horizontal axis. $(B)$ Production of IL-2 from human T-cells. Supernates were assayed on T lymphoblasts (27) in quadruplicate. The mixture of PHA plus hrIL-1 was directly assayed without prior incubation with $\mathrm{T}$ cells (indicated as $0 \mathrm{~d}$ ) and the amount of in situ IL-2 generation is reflected by the difference in $3 \mathrm{~d}$ and $0 \mathrm{~d}$. The asterisks indicate *, level of significance between the values at $3 \mathrm{~d}$ and $0 \mathrm{~d}$ using a paired $t$ test. 


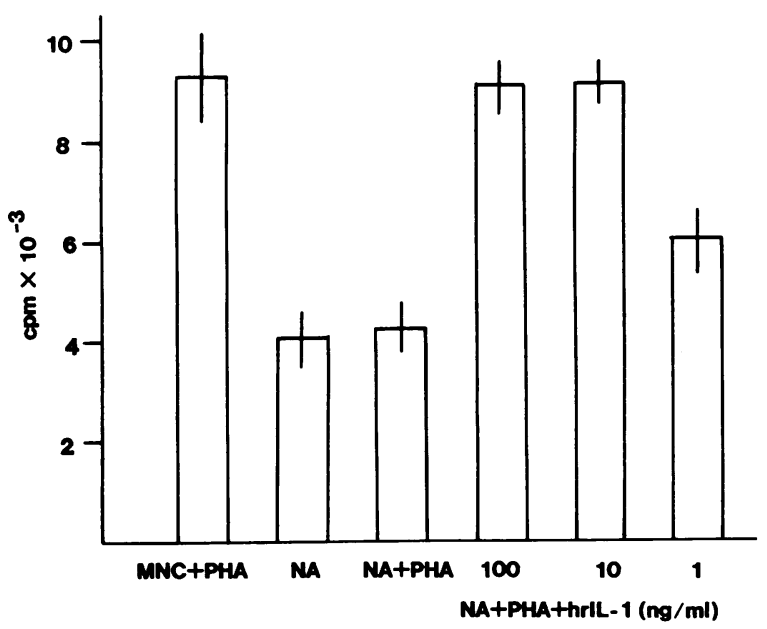

Figure 4. Generation of IL-2 from NA cells stimulated with hrIL-1 and PHA. NA were prepared by adherence and two passages over nylon wool and incubated with or without PHA (see Methods). After 48 $\mathrm{h}$ the supernatants were assayed for IL-2 using CTLL cells in quadruplicate. The data show a dilution of supernatants of 1:16.

Fever in mice. Endotoxin-resistant mice $(\mathrm{C} 3 \mathrm{H} / \mathrm{HeJ})$ were used in these studies. To rule out endotoxin contamination, the concentration in the purified hrIL-1 was determined by a limulus amebocyte lysate assay that had a sensitivity of $20 \mathrm{pg} / \mathrm{ml}$. Endpoint determinations using the clot-forming method revealed that hrIL-1 contained $20 \mathrm{pg} / \mu \mathrm{g}$ of IL- 1 protein. $\mathrm{C} 3 \mathrm{H} / \mathrm{HeJ}$ mice used under the conditions of this study develop fever (maximum temperature, $\mathrm{T}_{\max }=0.4^{\circ} \mathrm{C}$ ) after the injection of $500 \mathrm{ng}$ per 25 $\mathrm{g}$ mouse of $E$. coli endotoxin. As shown in Fig. $6 A$, the hrIL-1 induces a brisk, monophasic fever in prewarmed mice. Heating the sample resulted in loss of pyrogenicity. The decrease in body temperature that occurred after the injection of heat-inactivated hrIL-1 is frequently observed in studies using prewarmed mice or rats following the injection of nonpyrogenic agents. This may be, in part, due to removal of the animals from their thermoneutral environment during the injection procedure. The dose response for the pyrogenic response is illustrated in Fig. $6 \mathrm{~B}$. Similar to previous studies on human monocyte IL- 1 in the murine fever model, increasing the dose of pyrogen often produces less fever (28).

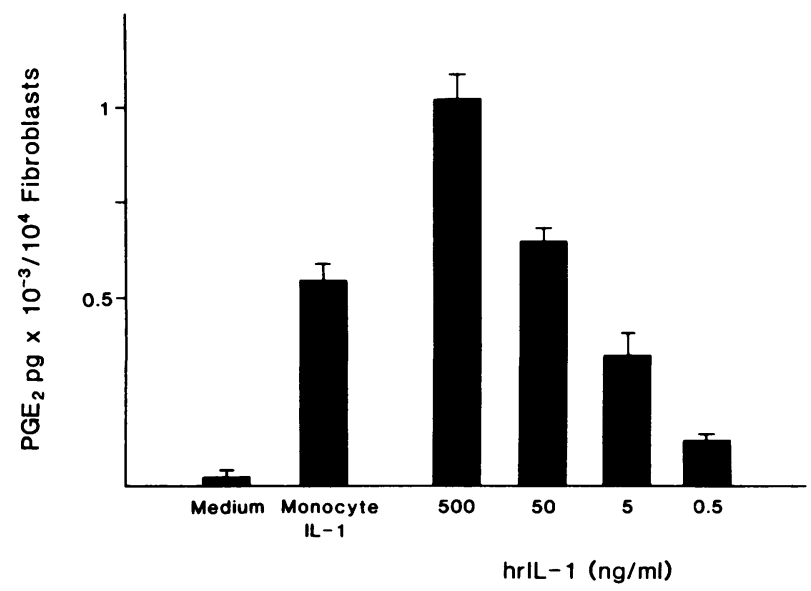

Figure 5. Human dermal fibroblast $\mathrm{PGE}_{2}$ production. hrIL-1 was incubated for $24 \mathrm{~h}$ in duplicate wells and $\mathrm{PGE}_{2}$ levels determined as described (30).
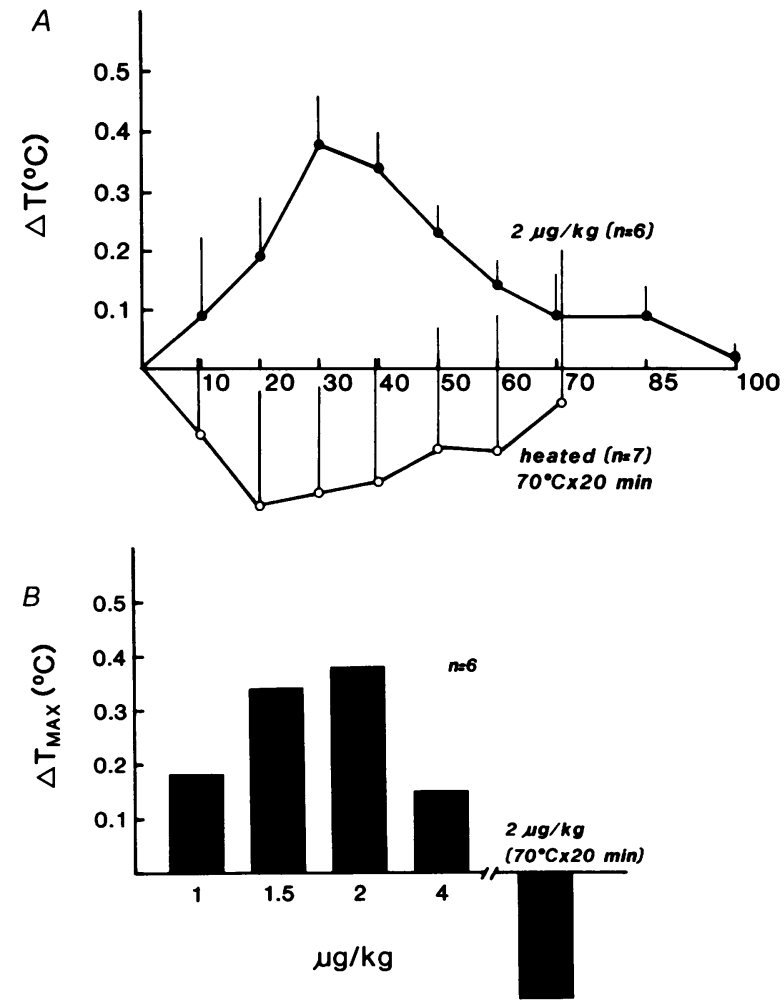

Figure 6. hrlL-1 fever in $\mathrm{C} 3 \mathrm{H} / \mathrm{HeJ}$ mice. $(A)$ Mean fever curve in mice injected with hrIL-1. $(B)$ Dose-response of fever in mice given hrIL-1.

Fever in rabbits. Rabbits injected intravenously with hrIL1 (amino acids 71-269) developed typical monophasic fevers that reached peak temperature elevations $\sim 54$ min after intravenous injection (Fig. 7). Preincubation with polymyxin B (250 $\mu \mathrm{g} / \mathrm{ml}$ ) inhibits the pyrogenic property of endotoxins but did not reduce the fever produced by hrIL-1. Heating for $30 \mathrm{~min}$ at $70^{\circ} \mathrm{C}$, a procedure that does not affect the biological properties of bacterial endotoxins, results in loss of pyrogenicity of IL-1 derived from mammalian cells $(5,9,12)$ and abolished the pyrogenicity of hrlL-1. In other experiments, 5 daily injections of hrIL-1 in rabbits did not induce pyrogenic tolerance (data not shown).

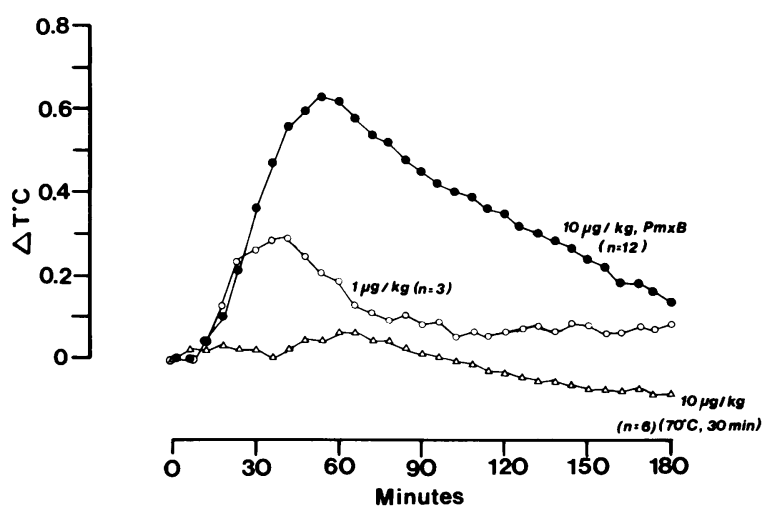

Figure 7. hrIL-1 fever in rabbits. Mean fevers following intravenous injections of hrIL-1 $(24,500 \mathrm{~mol} w \mathrm{w})$ into rabbits. The numbers of rabbits in each group are indicated in parentheses. Heated hrIL-1 was not pretreated with polymyxin B. 
In additional fever experiments, the hrIL-1 injected was the shorter form (amino acids 112-269, 17,500 mol wt), which contained $\sim 60 \mathrm{pg}$ of endotoxin/mg of IL-1 protein. This hrIL-1 was 50 -fold more pyrogenic in rabbits than the larger hrIL-1 (mol wt 24,500) containing the 46 precursor amino acids (compare Fig. 7 with Fig. 8). The murine T cell responses were similarly increased 50 -fold.

\section{Discussion}

The object of these studies was to establish that homogeneous preparations of human IL-1 purified from a recombinant strain of $E$. coli are biologically active in assays of both immunological function and inflammatory responses. Although the hrIL-1 used in these studies will need to be further evaluated for its ability to induce physiologic and metabolic changes associated with acute-phase responses, the data presented in this report support the concept that recombinant human IL-1 functions as a factor that promotes mitogen-driven T-cell blastogenesis and IL-2 production as well as induces fever and acts as a mediator of inflammation. Furthermore, these properties are destroyed by mild heating, which is characteristic of monocyte-derived IL-1.

The human IL-1 encoded by the precursor cDNA is unique in that it lacks a clear signal peptide that would indicate a likely processing site for the N-terminus. A murine IL-1 cDNA is similar in that it encodes for a similar size precursor and that it also lacks a signal peptide. Recent studies of the $\mathrm{N}$-terminus amino acid sequence of human monocyte-derived IL-1 with a pI of 7 have indicated that the cleavage of the precursor at the alanine (amino acid 117) is the likely N-terminus of the IL-1 found in supernates of stimulated monocytes (24). The IL-1 expressed in the recombinant $E$. coli and tested in the present study contains 46 of the 116 amino acids that are part of the precursor peptide. Several investigators have isolated peptides with molecular weights between 38,000 and 30,000 employing gel-filtration chromatography, and which exhibit many of the same IL-1 bio-

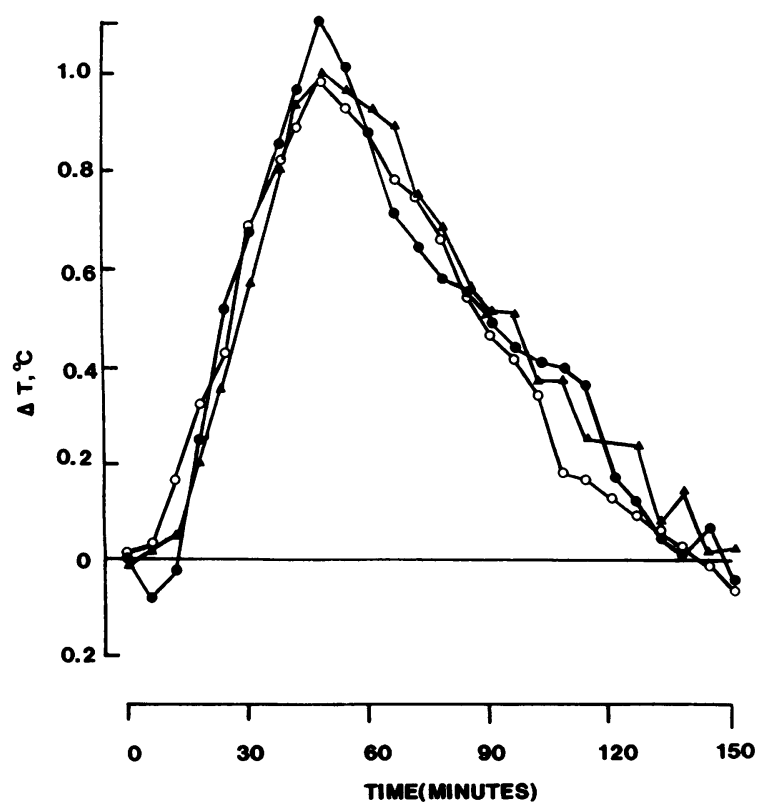

Figure 8. hrIL-1 fever in rabbits. Individual rabbit responses to hrIL-1 (mol wt 17,500) following an intravenous injection of $500 \mathrm{ng} / \mathrm{kg}$ are shown. Polymyxin B or protein stabilizers were not included. logical activities reported for the 15,000-17,000-mol wt size (12$14,31,32)$. Although some reports indicate that the human IL1 pI 7 form without cleavage of the precursor peptide has little biological activity (20), the present study establishes that the proximal 46 amino acids of the precursor peptide do not prevent biological activity in the assays used in these studies. This observation supports those of other investigators who have reported multiple biological activities of large molecular weight IL-1s. Since hrIL-1 functions indistinguishably from that of monocyte IL-1, we conclude that the extra amino acids derived from the precursor sequence do not prevent biological activity.

These additional amino acids may affect biological potency of the material, however. Nevertheless, the specific activity of the hrIL- 1 from $E$. coli $\left(5 \times 10^{6}\right.$ half-maximal units $\left./ \mathrm{mg}\right)$ is nearly the same as that for recombinant murine IL-1 (21). The murine recombinant IL-1 expressed in that study did not contain any precursor sequences. A recent report on the specific activity of purified human monocyte IL-1 with a pI of 7 indicates a specific activity $4.3 \times 10^{7} \mathrm{U} / \mathrm{mg}$ protein (8). By removing all but five of the precursor amino acids ( $\mathrm{N}$-terminus at alanine position 112 compared with the natural $\mathrm{N}$-terminus at alanine position 117), we observed a 50-fold increase in the specific activity of the hrIL-1 for both murine T cell stimulation as well as in pyrogenicity in rabbits. Cleaving the precursor peptides and producing hrIL-1 with a N-terminus closer to that of the natural IL-1 clearly increased the activities in these models but the shorter hrIL-1 did not have a significantly increased specific activity on dermal fibroblasts (data not shown). This may be due to the fact that some cell culture conditions provide sufficient proteases to cleave the precursor amino acids; alternatively, the precursor polypeptides may affect the potency of IL-1 for certain cells.

The specific activity of hrIL-1 may be affected by several conditions including the denaturization during extraction and purification, the additional amino terminal amino acids, and the lack of glycosylation. To isolate the IL-1 from the recombinant $E$. coli, denaturing conditions were employed. Refolding of the molecule may not be complete or isolation procedures may partially inactivate sites critical for biological activity. The lack of glycosylation by $E$. coli may influence the specific activity or solubility of hrIL-1. The peptide sequence of the IL-1 indicates a likely glycosylation site but the nonglycosylated form used in these studies establishes that the immunologic and inflammatory properties of IL-1 are maintained. Murphy was unable to show that the charge heterogeneity of rabbit IL-1s was due to glycosylated variants (33). Studies presently underway using mammalian cell-derived recombinant IL- 1 will be able to clarify this issue further.

Many biological properties of IL-1 are shared with bacterial endotoxins. It is thus important to exclude endotoxin from any IL-1 preparation, particularly recombinant IL-1 produced in $E$. coli. Although the preparations used in the present study had low endotoxin content $(20 \mathrm{pg} / \mu \mathrm{g})$ as determined by the Limulus amebocyte lysate assay, we used several methods to demonstrate that the biological effects of hrIL- 1 were not due to any undetected endotoxin. The fibroblast $\mathrm{PGE}_{2}$ stimulation assay (30) and $\mathrm{C} 3 \mathrm{H} / \mathrm{HeJ}$ mice are highly insensitive to endotoxins. Heating hrIL-1 to $70^{\circ} \mathrm{C}$ destroyed its pyrogenicity in mice and rabbits and polymyxin B had no effect on hrIL-1. Nevertheless, endotoxins are potent pyrogens and produce small fevers (minimum pyrogen dose) in rabbits at $3 \mathrm{ng} / \mathrm{kg}$. The shorter hrIL-1 (mol wt 17,500 ) used in the studies contained $\sim 60 \mathrm{pg}$ of endotoxin $/ \mathrm{mg}$ of IL-1. At the doses of this IL-1 given to rabbits $(500 \mathrm{ng} / \mathrm{kg})$, 
that would be equivalent to $30 \mathrm{fg}$ endotoxin $/ \mathrm{kg}$. Thus, there can no longer be any question that IL- 1 is an endogenous pyrogen and that its pyrogenic properties are not due to contaminating endotoxins. These studies clearly demonstrate that hrIL-1 possesses multiple biologic activities attributed to purified material obtained from blood monocytes and that the properties of $\mathrm{T}$ cell activation and induction of inflammatory responses reside in a single polypeptide.

Note added in proof. IN additional fever experiments, we injected the 17,500-mol wt hr IL-1 into 6 rabbits and observed a mean fever peak of $0.68 \pm 0.07^{\circ} \mathrm{C}$ following a dose of $100 \mathrm{ng} / \mathrm{kg}$.

\section{Acknowledgments}

The authors thank Walter O. Fredericks of Cistron Technology, Inc. and Thomas Fraser of Repligen Corp. for their encouragement of these studies. Special thanks to Dr. Takashi Ikejima, Scott Oroncle, Redentor Maxwell, and Lorraine Barrie for assistance.

Supported by National Institutes of Health grants AI 15614 and CA 39489 from the U. S. Public Health Service and by Cistron Technology, Inc., Pine Brook, NJ.

\section{References}

1. Nathan, S. B., H. W. Murray, and Z. A. Cohn. 1980. The macrophage as an effector cell. N. Engl. J. Med. 303:622-626.

2. Dinarello, C. A. 1984. Interleukin-1. Rev. Infect. Dis. 6:51-95.

3. Dinarello, C. A. 1984. Interleukin-1 and the pathogenesis of the acute phase response. $N$. Engl. J. Med. 311:1413-1418.

4. Krane, S. M., S. R. Goldring, and J.-M. Dayer. 1982. Interactions among lymphocytes, monocytes, and other synovial cells in the rheumatoid synovium. In Lymphokines. E. Pick and M. Lany, editors. Academic Press, New York. 75-136.

5. Rosenwasser, L. J., C. A. Dinarello, and A. S. Rosenthal. 1979. Adherent cell function in murine T-lymphocyte antigen recognition. IV. Enhancement of murine T-cell antigen recognition by human leukocytic pyrogen. J. Exp. Med. 150:709-714.

6. Murphy, P. A., P. L. Simon, and W. F. Willoughby. 1980. Endogenous pyrogens made by rabbit peritoneal exudate cells are identical with lymphocyte activating factors made by rabbit alveolar macrophages. J. Immunol. 124:2498-2501.

7. Kampschmidt, R. F. 1984. Infection, inflammation and interleukin-1. Lymphokine Res. 2:97-110.

8. Matsushima, K., S. K. Durum, E. S. Kimball, and J. J. Oppenheim. 1985. Purification of human interleukin- 1 and identity of thymocyte comitogenic factor, fibroblast proliferation factor, acute-phase protein-inducing factor and endogenous pyrogen. Cell. Immunol. 92:290-302.

9. Hanson, D. F., and P. A. Murphy. 1984. Demonstration of interleukin-1 activity in apparently homogeneous specimens of the pI 54 form of rabbit endogenous pyrogen. Infect. Immun. 45:483-490.

10. Dinarello, C. A., H. A. Bernheim, J. G. Cannon, G. LoPreste, S. J. C. Warner, A. C. Webb, and P. E. Auron. 1985. Purified, ${ }^{35}$ S-met, ${ }^{3} \mathrm{H}$-leu-labeled human monocyte interleukin-1 with endogenous pyrogen activity. Br. J. Rheumatol. 24:59-64.

11. Lachman, L. B. 1983. Human interleukin-1: purification and properties. Fed. Proc. 42:2639-2644.

12. Dinarello, C. A., N. P. Goldin, and S. M. Wolff. 1974. Demonstration and characterization of two distinct human leukocytic pyrogens. J. Exp. Med. 139:1369-1381.

13. Wood, D. D., E. K. Bayne, M. B. Goldring, M. Gowen, D. Hamerman, J. L. Humes, E. J. Ihrie, P. E. Lipsky, and M.-J. Staruch. 1985. The four biochemically distinct species of human interleukin-1 all exhibit similar biologic activities. J. Immunol. 134:895-902.

14. Sahasrabuddhe, C. G., C. A. Dinarello, B. Martin, and A. L. Maizel. 1985. Intracellular human interleukin-1: a precursor for the secreted monokine. Lymphokine Res. 4:205-213.
15. Saklatvala, J., J. Pilsworth, S. J. Sarsfield, J. Gavrilovic, and J. K. Heath. 1984. Pig catabolin is a form of interleukin-1. Biochem. J. 224:461-466.

16. Kimball, E. S., S. F. Pikeral, J. J. Oppenheim, and J. L. Rossio. 1984. Interleukin-1 activity in normal urine. J. Immunol. 133:256-261.

17. Dinarello, C. A., G. H. A. Clowes, Jr., A. H. Gordon, C. A. Saravis, Sand S. M. Wolff. 1984. Cleavage of human interleukin-1: isolation of a peptide fragment from plasma of febrile humans and activated monocytes. J. Immunol. 133:1332-1338.

18. Cannon, J. G., and C. A. Dinarello. 1985. Increased plasma interleukin-1 activity in women after ovulation. Science (Wash. DC). 227: 1247-1249.

19. Auron, P. E., A. C. Webb, L. J. Rosenwasser, S. F. Mucci, A. Rich, S. M. Wolff, and C. A. Dinarello. 1984. Nucleotide sequence of human monocyte interleukin-1 precursor cDNA. Proc. Natl. Acad. Sci. USA. 81:7907-7911.

20. March, C. J., B. Mosley, A. Larsen, D. P. Cerretti, G. Braedt, V. Price, S. Gillis, C. S. Henney, S. R. Kronheim, K. Grabstein, P. J. Conlon, T. P. Hopp, and D. Cosman. 1985. Cloning, sequence and expression of two distinct human interleukin-1 complementary DNAs. Nature (Lond.). 315:641-646.

21. Lomedico, P. T., U. Gubler, C. P. Hellmann, M. Dukovich, J. G. Giri, Y.-C. E. Pan, K. Collier, R. Semionow, A. O. Chua, and S. B. Mizel. 1984. Cloning and expression of murine interleukin-1 cDNA in Escherichia coli. Nature (Lond.). 312:458-462.

22. Webb, A. C., P. E. Auron, A. Rich, L. J. Rosenwasser, S. M. Wolff, and C. A. Dinarello. 1985. Molecular cloning of human interleukin- 1 precursor cDNA and its expression in monkey cells. In: Molecular and Cellular Biology of Lymphokines. IV. International Lymphokine Conference. C. Sorg and A. Schimpl, editors. Academic Press, New York. 685-695.

23. Dinarello, C. A., L. Renfer, and S. M. Wolff. 1977. Human leukocytic pyrogen: purification and development of a radioimmunoassay. Proc. Natl. Acad. Sci. USA. 74:4624-4627.

24. Van Damme, J., M. De Ley, G. Opendenakker, A. Billiau, and P. DeSomer. 1985. Homogeneous interferon-inducing $22 \mathrm{~K}$ factor is related to endogenous pyrogen and interleukin-1. Nature (Lond.). 314: 266-268.

25. Kaye, J., S. Porcelli, J. Fite, B. Jones, and C. A. Janeway, Jr. 1983. Both a monoclonal antibody an antisera specific for determinants unique to individual cloned helper T-cell lines can substitute for antigen and antigen-presenting cells in the activation of T-cells. J. Exp. Med. 158:836-843.

26. Kaye, J., S. Gillis, S. B. Mizel, E. M. Shevach, T. R. Malek, C. A. Dinarello, L. B. Lachman, and C. A. Janeway, Jr. 1984. Growth of a cloned helper T-cell line induced by a monoclonal antibody specific for the antigen receptor: interleukin-1 is required for the expression of receptors for interleukin-2. J. Immunol. 133:1339-1344.

27. Gillis, S., M. Ferm, W. Ou, and K. Simth. 1978. T cell growth factor: parameters of production and a quantitative microassay for activity. J. Immunol. 120:2027-2031.

28. Bodel, P., and H. Miller. 1978. A new sensitive method for detecting human endogenous pyrogen. Inflammation. 3:103-110.

29. Cannon, J. G., and C. A. Dinarello. 1985. Multiple interleukin1 activities in luteal phase human plasma. Br. J. Rheumatol. 24:226229.

30. Bernheim, H. A., and C. A. Dinarello. 1985. Effects of purified human interleukin-1 on the release of prostaglandin $\mathrm{E}_{2}$ from fibroblasts. Br. J. Rheumatol. 24:122-127.

31. Dinarello, C. A., K. Bendtzen, and S. M. Wolff. 1982. Studies on the active site of human leukocytic pyrogen. Inflammation. 6:63-78.

32. Kampschmidt, R. F., and L. A. Pulliam. 1978. Effect of human monocyte pyrogen on plasma iron, plasma zinc, and blood neutrophils. Proc. Soc. Exp. Biol. Med. 158:32-35.

33. Murphy, P. A., T. A. Cebula, and B. E. Windle. 1981. Heterogeneity of rabbit endogenous pyrogen is not attributable to glycoslylated variants of a single polypeptide chain. Infect. Immun. 34:184-190. 